\title{
Pneumonia adquirida na comunidade em crianças e vacinação antipneumocócica 10 valente: atualização
}

\section{Community-acquired pneumonia in children and 10-valent anti- pneumococcal vaccination: update}

\author{
Maria de Fátima Bazhuni Pombo $\operatorname{March}^{1}$ e Alexandre Nicolau Galvão ${ }^{1}$ \\ 'Universidade Federal Fluminense
}

\section{Palavras-chave:}

Pneumonia; Criança; Vacinas pneumocócicas.

\section{Resumo}

Introdução: a incorporação da vacina antipneumocócica 10 valente no calendário vacinal brasileiro em 2010, no Programa Nacional de Imunizações, gerou a redução de doenças pneumocócicas, como meningites e pneumonia adquirida na comunidade, e da colonização de orofaringe e mucosa nasal pelo pneumococo (Streptococcus pneumoniae). Objetivo: realizar um estudo de revisão sobre etiologia, quadro clínico, complicações, conduta e medidas preventivas das pneumonias adquiridas na comunidade, e discutir a resistência do pneumococo aos antibióticos. Fontes de dados: livros, artigos e diretrizes considerados relevantes nos últimos 21 anos, indexados nos bancos de dados PubMed, Medline, Lilacs e SciELO, com os descritores 'pneumonia', 'criança' e 'vacinas pneumocócicas' nas línguas portuguesa, inglesa e espanhola. Síntese dos dados: todos os casos de pneumonia adquirida na comunidade grave necessitam de hospitalização e, em geral, uso de ampicilina ou penicilina cristalina como primeira escolha. A amoxicilina é indicada no tratamento ambulatorial na dose de $50 \mathrm{mg} / \mathrm{kg} / \mathrm{dia}$ de $8 \mathrm{em} 8$ horas. Estudos nacionais identificaram que um ano após sua introdução na rede pública houve redução das hospitalizações de crianças por pneumonia adquirida na comunidade no Brasil. Conclusões: o tratamento das pneumonias adquiridas na comunidade ainda é um desafio e a instituição de um fluxograma de tratamento pode ser útil, priorizando a penicilina e seus derivados, ainda considerados drogas de escolha em todas as diretrizes nacionais e internacionais. O estabelecimento da vacina antipneumocócica 10 valente no calendário vacinal trouxe redução das internações por pneumonia adquirida na comunidade e deve ser incentivada pelo pediatra.

\author{
Keywords: \\ Pneumonia; Child; Pneumococcal vaccines.
}

\begin{abstract}
Introduction: the incorporation of 10-valent pneumococcal conjugate vaccine to the Brazilian vaccination calendar in 2010, by the National Immunization Program, led to the reduction of pneumococcal diseases such as meningitis and community-acquired pneumonia, and colonization of the oropharynx and nasal mucosa by pneumococcus (Streptococcus pneumoniae). Objective: to carry out a review study on etiology, clinical picture, complications, conduct and preventive measures of community-acquired pneumonia, and to discuss pneumococcus resistance to antibiotics. Data source: books, articles and guidelines considered relevant from the last 21 years, indexed in PubMed, Medline, Lilacs and SciELO databases, with the descriptors 'pneumonia', 'child' and 'pneumococcal vaccines' in the Portuguese, English and Spanish languages. Data synthesis: all cases of severe community-acquired pneumonia require hospitalization and, in general, the use of ampicillin or crystalline penicillin as the first choice. Amoxicillin is indicated for outpatient treatment at a dose of $50 \mathrm{mg} / \mathrm{kg}$ / day of 8 in 8 hours. National studies identified that one year after the introduction of the 10-valent pneumococcal conjugate vaccine in the public health network there was a reduction of hospitalizations of children by community-acquired pneumonia in Brazil. Conclusions: the treatment of community-acquired pneumonia is still a challenge and the establishment of a guideline can be useful, prioritizing penicillin and its derivatives, that are still the drugs of choice all over the world. The establishment of 10 -valent pneumococcal conjugate vaccine in the immunization schedule led to a reduction in community-acquired pneumonia admissions and should be encouraged by the pediatrician.
\end{abstract}




\section{INTRODUÇÃO}

As infecções respiratórias agudas (IRA) na infância são objeto de preocupação em todo o mundo. A maioria das crianças tem de quatro a seis IRA por ano, principalmente nas áreas urbanas.

As IR A correspondem à quarta parte de todas as doenças e mortes entre crianças nos países em desenvolvimento. Cerca de 2-3\% das IRA evoluem para infecção do parênquima pulmonar, correspondendo às pneumonias. ${ }^{1-3}$ Destas, $10-20 \%$ evoluirão para óbito, contabilizando 1,2 milhões de óbitos por ano no mundo. O Brasil concentrava grande parte dos casos de pneumonia em menores ou crianças com 5 anos no início da década de $2000 .^{1-3}$

A elevada morbimortalidade das IRA vem sendo estudada desde a década de 1970, com investigações pioneiras de Bulla e Hitze em 1978 até o presente, pois, 40 anos depois, ainda é um desafio do ponto de vista da saúde pública. Ao longo desses anos, pacientes pediátricos, por sua vulnerabilidade às infecções, são o grupo prioritário para se beneficiar das condutas padronizadas que visem reduzir a mortalidade por uma das IRA mais temidas: a pneumonia. ${ }^{4}$

Os quadros de pneumonia na infância que têm interesse do ponto de vista de mortalidade são, em geral, as pneumonias adquiridas na comunidade (PAC). Como o nome indica, são afecções que acometem crianças previamente hígidas e que vêm desenvolvendo as atividades normais para sua idade, até serem acometidas pelo quadro agudo, de maior ou menor gravidade, das PAC., 5

No Brasil a principal causa de hospitalização em pediatria é a PAC. Esta é responsável por elevada morbimortalidade no país e no mundo. A mortalidade por PAC foi responsável por cerca de $5 \%$ das mortes entre menores de 5 anos. ${ }^{3,4} \mathrm{O}$ principal agente etiológico das PAC em menores de 5 anos é o Streptococcus pneumoniae (pneumococo), de acordo com estudos nacionais e internacionais. ${ }^{4}$

A vacinação conjugada antipneumocócica é utilizada desde o ano 2000 nos Estados Unidos, primeiro como vacina conjugada antipneumocócica 7 valente (PCV7), substituída em 2010 pela vacina pneumocócica 13 valente (PCV13). Também em 2010, a vacina antipneumocócica 10 valente (PCV10) foi implantada no calendário vacinal brasileiro, incluindo os mesmos sorotipos da PCV7 (4, 6B, 9V, 14, 18C, 19F, 23F) e acrescida dos sorotipos 1, 5 e 7F. ${ }^{7}$ Assim, com a incorporação desta vacinação no Programa Nacional de Imunizações (PNI) do Brasil, observou-se a redução de doenças pneumocócicas, como meningite e PAC, bem como de colonização de orofaringe e mucosa nasal por Streptococcus pneumoniae.,8

\section{MÉTODO}

Trata-se de um estudo de revisão integrativa com a utilização de artigos indexados nos últimos 21 anos nos bancos de dados eletrônicos PubMed, Medline, Lilacs e SciELO e adoção dos descritores 'pneumonia', 'criança' e 'vacinas pneumocócicas' nas línguas portuguesa, inglesa e espanhola.

Foram escolhidos os artigos mais expressivos para atender às normas de publicação. Também foram selecionados livros, diretrizes nacionais e internacionais e textos considerados relevantes para a redação desta revisão.

\section{RESULTADOS}

Os dados coletados na revisão de literatura serão apresentados considerando a importância das PAC na infância, suas características clínicas, etiológicas, diagnósticas e preventivas. Também serão propostas condutas na forma de fluxogramas de tratamento que visam facilitar o manuseio dos casos a níveis hospitalar e ambulatorial.

\section{PAC: DEFINIÇÃO}

Pneumonia é a inflamação do parênquima pulmonar, causada, na maioria das vezes, por micro-organismos e raramente por agentes não infecciosos. Há um processo inflamatório, que é a resposta do hospedeiro ao agente agressor. Em geral, o diagnóstico será baseado em dados clínicos e o tratamento empírico, de acordo com dados epidemiológicos da região. O termo 'PAC' refere-se à pneumonia que ocorre em crianças não hospitalizadas no último mês, portanto não colonizadas por germes hospitalares e, sim, por aqueles provenientes do meio domiciliar, escolar e comunitário. ${ }^{5,9}$ Quando ocorre após 48 horas da admissão hospitalar, é denominada 'pneumonia adquirida no hospital' (PAH).

As variáveis de risco para a PAC relacionadas ao hospedeiro são: desnutrição, baixa idade, comorbidades, baixo peso ao nascer, episódios prévios de sibilos e pneumonias, ausência de aleitamento materno, vacinação incompleta e infecções virais respiratórias. Todos estes fatores interferem na proteção gerada por essas barreiras e facilitam a ocorrência das PAC. ${ }^{10-14}$

\section{ETIOLOGIA}

As PAC podem ser causadas por vírus, bactérias e ambos (coinfecções); variam de acordo com a faixa etária do paciente e as estações do ano (sazonalidade). Em todas as idades os vírus têm papel importante, sendo 
o vírus sincicial respiratório (VSR) o mais frequente. ${ }^{4}$

A incorporação tecnológica da reação em cadeia da polimerase (PCR) trouxe à tona o papel dos vírus nas IRA da infância, permitindo identificar com mais facilidade e rapidez vírus já conhecidos e novos vírus, ou vírus emergentes (como é o caso do Metapneumovírus e Bocavírus). O VSR é o agente mais encontrado em menores de 5 anos. Dentre as bactérias, podemos citar Streptococcus pneumoniae (pneumococo), Haemophilus influenzae e Staphylococcus aureus.

No quadro abaixo seguem os agentes etiológicos mais frequentes por faixa etária. O pneumococo destaca-se como um dos maiores causadores de PAC em todas as idades. A ampla imunização fez com que diminuísse a incidência mundial do Haemophilus influenzae. Staphylococcus aureus está relacionado, principalmente, à baixa faixa etária, com infecções cutâneas e gravidade clínica, além de piora rápida e progressiva. 5,6,15-18

Outras bactérias também podem causar PAC, como Mycoplasma pneumoniae e Chlamydia pneumoniae. São consideradas pneumonias atípicas, com características clínicas próprias e mais frequentes em maiores de 5 anos. ${ }^{9}$

Atualmente, alguns estudos demonstram que bactérias antes relacionadas apenas com quadros de PAH como Staphylococcus aureus resistente à meticilina ou MRSA - podem causar PAC, independentemente de internação hospitalar prévia. ${ }^{19,20}$
O quadro 1 descreve os principais agentes causadores de PAC segundo a faixa etária do paciente. ${ }^{4}$

Estudos mostram incidência maior de PAC no período do inverno (dezembro e janeiro nos EUA) e menor no verão, associando a variação das pneumonias às variações virais. ${ }^{21}$ No Brasil, estudos evidenciaram um pico de PAC causado por parainfluenza na primavera e de VSR no outono. ${ }^{22}$

\section{QUADRO CLÍNICO E DIAGNÓSTICO}

O quadro clínico das PAC pode variar com a idade da criança, o estado nutricional, a presença de doença de base e o agente etiológico, podendo ser mais grave nas crianças mais jovens, desnutridas ou que apresentam comorbidades. Os principais sinais e sintomas são: febre, tosse, frequência respiratória (FR) elevada (taquipneia) e dispneia, de intensidades variáveis. A sibilância ocorre com maior frequência nas crianças com infecções virais ou por Mycoplasma pneumoniae ou Chlamydophila pneumoniae. ${ }^{20-24}$

PAC é diagnosticada em crianças menores de 5 anos com história clínica de tosse e/ou dificuldade respiratória há sete ou, no máximo, dez dias, por FR elevada e/ou tiragem subcostal. Em crianças menores de 2 meses, tanto a FR maior ou igual a 60 rpm quanto a tiragem subcostal são consideradas de alto valor preditivo de PAC grave. Nas crianças de 2 meses a 4 anos, os valores

\section{Quadro 1 - Descrição dos agentes causadores de PAC por faixa etária}

\begin{tabular}{|c|c|}
\hline IDADE & AGENTES ETIOLÓGICOS \\
\hline Período neonatal & $\begin{array}{l}\text { Estreptococo do grupo B } \\
\text { Enterobactérias } \\
\text { Citomegalovírus } \\
\text { Listeria monocytogenes } \\
\text { Staphylococcus aureus }\end{array}$ \\
\hline 3 semanas a 3 meses & $\begin{array}{l}\text { Chlamydia trachomatis } \\
\text { Vírus sincicial respiratório (VSR) } \\
\text { Parainfluenza } \\
\text { Streptococcus pneumoniae } \\
\text { Bordetella pertussis }\end{array}$ \\
\hline Lactentes e pré-escolares (< 5 anos) & $\begin{array}{l}\text { VSR, parainfluenza, influenza, adenovírus, rinovírus } \\
\text { Streptococcus pneumoniae } \\
\text { Haemophilus influenzae } \\
\text { Staphylococcus aureus } \\
\text { Mycoplasma pneumoniae } \\
\text { Mycobacterium tuberculosis }\end{array}$ \\
\hline Pré-escolares (> 5 anos) e adolescentes & $\begin{array}{l}\text { Streptococcus pneumoniae } \\
\text { Mycoplasma pneumoniae } \\
\text { Chlamydia pneumoniae } \\
\text { Mycobacterium tuberculosis }\end{array}$ \\
\hline
\end{tabular}

Fonte: Sociedade Brasileira de Pneumologia e Tisiologia. ${ }^{4}$ 
da FR indicativos de que a criança tenha PAC são maiores ou iguais a $50 \mathrm{rpm}$ se a criança tem 2 a 11 meses e maior ou igual a 40 se de 1 a 4 anos. A tiragem subcostal é considerada como sinal de PAC grave em crianças de 2 meses a 4 anos. ${ }^{5,20,23}$

A taquipneia pode estar associada a PAC em crianças com sibilos, mas a história de episódios prévios de sibilância leva ao possível diagnóstico de hiper-reatividade brônquica/asma. Por isso, nestes casos, a FR deve ser contada após o tratamento da sibilância que o paciente apresente com broncodilatadores e eventualmente corticosteroides sistêmicos. ${ }^{4,9}$

No recém-nascido as manifestações respiratórias são ainda menos evidentes. Costumam predominar os sinais gerais de sepse, como recusa do alimento, letargia, hipotonia, convulsões, vômitos, distensão abdominal, palidez, cianose, hipotermia, com grau variável de comprometimento respiratório (taquipneia, episódios de apneia, tiragem, batimento de asas do nariz e gemido). ${ }^{24}$

Nos lactentes e crianças pequenas, as PAC costumam iniciar-se com quadro febril brusco. À medida que o quadro progride, aparecem manifestações de maior gravidade: letargia, recusa alimentar, tiragem subcostal, taquipneia, gemido expiratório, cianose, distensão abdominal e taquicardia. ${ }^{4,24}$

Na pneumonia por Mycoplasma pneumoniae (causa mais frequente de pneumonia atípica), o início é gradual com mal-estar, febre, cefaleia e tosse irritativa, que se manifestam a partir do terceiro ao quinto dia de doença e acometem principalmente crianças em fase escolar. Trata-se de quadro insidioso com período de incubação de duas a três semanas, eventual tosse coqueluchoide e relatos de contactantes na família e na escola, além de ausência de resposta clínica ao tratamento habitual para PAC com betalactâmicos. Trata-se de PAC de evolução subaguda., ${ }^{9} 20$

Chlamydia trachomatis é outro agente causador de pneumonia afebril, principalmente nos lactentes nos seus quatro primeiros meses de vida nascidos, em geral, de parto normal. O quadro clínico caracteriza-se por início gradual e curso subagudo, com acessos prolongados de tosse intensa, taquipneia e estertores finos bilaterais. Chama a atenção o regular estado geral do paciente. Pode haver relato materno de leucorreia durante a época do parto.9,20,22

Assim, o diagnóstico da PAC é eminentemente clínico. Os principais sinais e sintomas são: febre, tosse, taquipneia (aumento da FR), dificuldade respiratória, com ou sem a presença de tiragem, e estertores crepitantes ou murmúrio vesicular abolido na ausculta pulmonar. De acordo com a Organização Mundial da Saúde (OMS), tosse e dificuldade respiratória em associação com taquipneia (sinal mais importante) permite o diagnóstico da PAC na prática pediátrica. ${ }^{4,9,22,23}$

As PAC também podem ser classificadas de acordo com a idade. Crianças com menos de 2 meses que, além de tosse e da dificuldade respiratória, apresentem FR elevada ( $\geq 60$ ), com ou sem tiragem subcostal, devem ser consideradas como pacientes com pneumonia grave e internadas para tratamento hospitalar. ${ }^{22,25}$

Os pacientes com mais de 2 meses são separados em dois grupos:

a) pneumonia (apenas FR aumentada para a idade) - requerem tratamento ambulatorial com antibioticoterapia;

b) pneumonia grave (FR aumentada com presença de tiragem subcostal) - devem ser encaminhados para internação hospitalar.

Outros sinais de PAC que indicam gravidade e necessidade de internação são: saturação de oxigênio menor que $92 \%$; abolição do murmúrio vesicular, com possibilidade ou confirmação radiológica de complicações, como derrame pleural (DP) e empiema; desnutrição grave; sonolência; rebaixamento do nível de consciência e recusa alimentar.

Segundo revisões sistemáticas, os "sinais de perigo" apontados pela OMS há décadas indicam internação hospitalar imediata do paciente, pois presumem doença muito grave. Tais sinais em crianças menores de 2 meses são: FR maior ou igual a $60 \mathrm{rpm}$; tiragem subcostal; febre alta; recusa do seio materno por mais de três mamadas; sibilância; estridor em repouso; sensório alterado com letargia; sonolência anormal ou irritabilidade excessiva. Entre as maiores de 2 meses os sinais são: tiragem subcostal; estridor em repouso; recusa de líquidos; convulsão; alteração do sensório; e vômito de tudo que lhe é oferecido. ${ }^{22}$

A realização de radiografia de tórax só é recomendada nos casos graves que demandam internação hospitalar. Em geral, consolidação alveolar (Figura 1), pneumatoceles, derrames pleurais (Figura 2) e abscessos sugerem etiologia bacteriana. O padrão intersticial (Figura 3) está mais frequentemente associado a vírus Mycoplasma pneumoniae ou Chlamydia pneumoniae. Estes são agentes causadores de pneumonias atípicas. ${ }^{22}$ Seguem nas ilustrações alguns exemplos de padrões radiológicos. 
Figura 1 - Consolidação alveolar

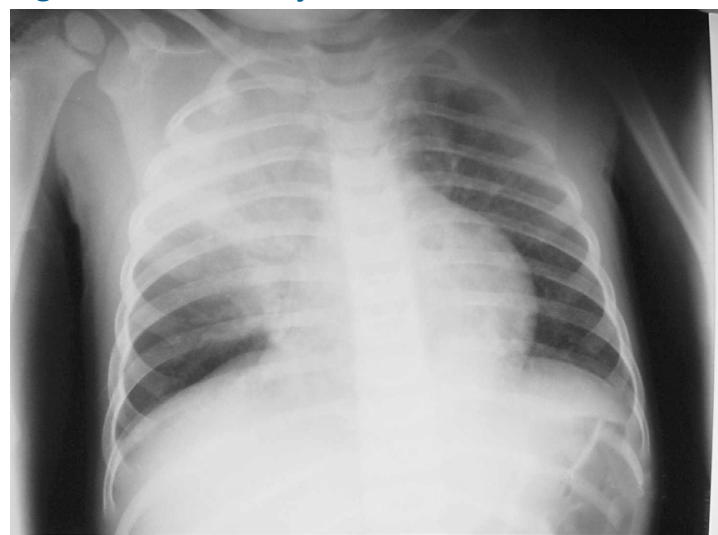

Fonte: Radiografia pertencente ao Serviço de Pneumologia do Instituto de Puericultura e Pediatria Martagão Gesteira da Universidade Federal do Rio de Janeiro (2018).

Figura 2 - Derrame pleural

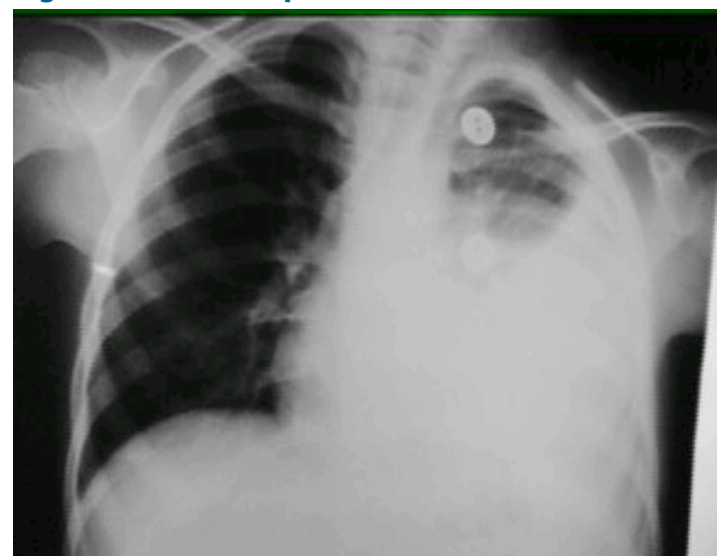

Fonte: Radiografia pertencente ao Serviço de Pneumologia do Instituto de Puericultura e Pediatria Martagão Gesteira da Universidade Federal do Rio de Janeiro (2018).

Figura 3 - Infiltrado intersticial

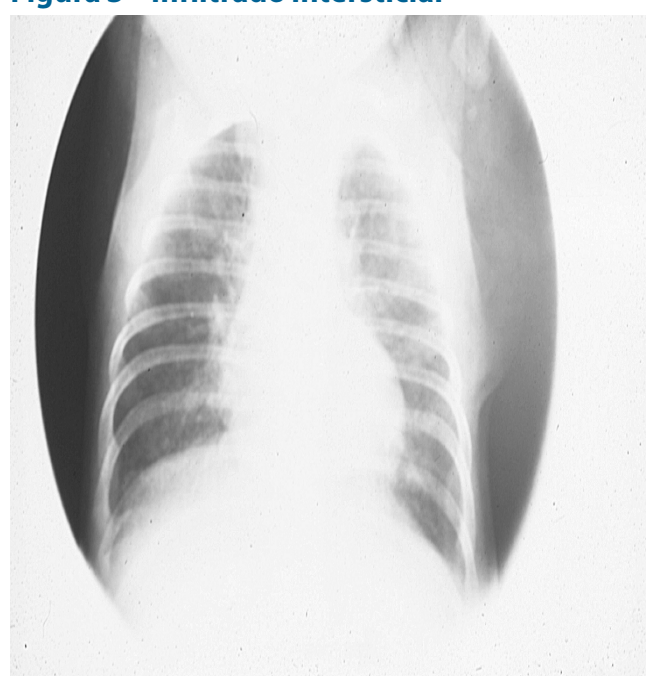

Fonte: Radiografia pertencente ao Serviço de Pneumologia do Instituto de Puericultura e Pediatria Martagão Gesteira da Universidade Federal do Rio de Janeiro (2018).

Os demais exames complementares são inespecíficos e de emprego questionável. O leucograma, em geral, nos casos bacterianos, mostra leucocitose, neutrofilia e a ocorrência de formas jovens. A eosinofilia acima ou igual a 300 células $/ \mathrm{mm}^{3}$ pode ocorrer na maioria dos pacientes com infecção por Chlamydia trachomatis. Proteína C reativa (PC-R) maior ou igual a 40-100 mg ou níveis acima ou iguais a $0,75-2,0 \mathrm{ng} / \mathrm{ml}$ de procalcitonina sugerem etiologia bacteriana.

O diagnóstico microbiológico só é indicado nos casos de PAC grave, em crianças internadas ou quando a evolução do paciente é desfavorável. Para tal, um dos métodos é a hemocultura, embora sua positividade seja baixa (pode alcançar 35\% nos casos hospitalizados). Apesar disto, o exame é importante, especialmente em serviços de referência, pois o conhecimento do padrão de resistência/sensibilidade aos antimicrobianos, com destaque para o pneumococo, é crucial. O exame microbiológico é sempre recomendado nos casos de DP que permitam ser puncionados. A positividade do líquido pleural pode alcançar até $70 \%$, antes do início da antibioticoterapia. A cultura do escarro tem pouca utilidade prática, por não diferenciar infecção de colonização. 4,22,26

Os métodos sorológicos são úteis no diagnóstico das infecções por Mycoplasma pneumoniae, Chlamydia trachomatis e Chlamydia pneumoniae, quando houver elevação da IgM ou elevação de quatro vezes nos títulos da IgG, na fase aguda e na convalescência, respectivamente. Alguns vírus, como o VSR, adenovírus, parainfluenza e influenza, também podem ser diagnosticados pelo aumento acima ou de quatro vezes nos níveis de IgG, com intervalo de cerca de duas semanas.

A reação em cadeia da polimerase em tempo real (PCR-RT) pode auxiliar no diagnóstico de Mycoplasma pneumoniae, Chlamydophila pneumoniae, Chlamydia trachomatis, Legionella pneumophila, Staphylococcus aureus, vírus respiratórios, Bordetella pertussis, Mycobacterium tuberculosis e Streptococcus pneumoniae. São métodos caros, mais utilizados em pesquisas e não recomendados nos casos não complicados. .,9,20,26 $^{2}$

Os métodos invasivos, como broncoscopia, lavado broncoalveolar e biópsias pulmonares são indicados em situações excepcionais, quando a evolução da PAC for desfavorável.9,22

Exames complementares não são indicados de forma rotineira na maioria dos casos. Estes podem ser conduzidos sem radiografia de tórax, que deverá ser realizada na suspeita de complicações, como DP, e nos pacientes que necessitam internação. O mesmo ocorre em relação aos exames para confirmação etiológica, como hemocultura, cultura e análise do líquido pleural, exame de detecção viral e sorologia para Mycoplasma pneumoniae e Chlamydia pneumoniae. ${ }^{26}$ 


\section{COMPLICAÇÕES}

Em crianças, o DP é a complicação mais frequente da PAC bacteriana. No Brasil ocorre em aproximadamente $40 \%$ das crianças hospitalizadas por PAC. Pode ser definido como o acúmulo de líquido no espaço pleural resultante de desequilíbrio das forças que regulam a formação e reabsorção do líquido pleural ou de eventos patológicos na pleura. O DP infeccioso é um sinal de complicação de quadro pneumônico e é chamado DP parapneumônico (DPP). Seu reconhecimento precoce permite definir a melhor forma de tratamento, visando reduzir os riscos de morbidade e de mortalidade. ${ }^{22,26}$

Os DPP são exudatos que resultam da reação inflamatória da pleura. Iniciam-se como exudato reacional, de aspecto claro, não viscoso, com baixa celularidade e sem bactérias, com valores baixos de $\mathrm{pH}$, desidrogenase láctica (LDH) e glicose. Se o processo não for controlado, o DP pode se tornar complicado, com o aumento do volume de líquido, da celularidade pleural, da LDH e queda acentuada do $\mathrm{pH}$, podendo evoluir para empiema pleural.

Os agentes etiológicos do DPP são os mesmos das PAC não complicadas, em ordem de frequência: Streptococcus pneumoniae, Haemophilus influenzae e Staphylococcus aureus. Streptococcus pneumoniae é o principal agente encontrado, inclusive em lactentes. Apesar do aumento da frequência de pneumococo resistente à penicilina, não tem sido identificada maior incidência de complicações associadas às infecções causadas por cepas resistentes.

A radiografia de tórax na maioria das vezes é suficiente para investigação do DPP. As incidências posteroanterior, perfil e decúbito lateral com raios horizontais (incidência de Hjelm-Laurell) são as recomendadas. A ultrassonografia do tórax só está indicada nos casos de dúvida, ou para definir o melhor local para realização de toracocentese ou drenagem. A tomografia do tórax com contraste venoso é útil em casos especiais, auxiliando nos casos cirúrgicos. ${ }^{20,22,26}$

Sempre que houver possibilidade de toracocentese, o líquido pleural deve ser puncionado e examinado com testes bioquímicos, exame direto para bactérias, citologia diferencial de células e cultura para bactérias. Se o líquido não for purulento, a análise bioquímica pode auxiliar na detecção de empiema e direcionar quanto à necessidade de drenagem. A detecção de pus estabelece o diagnóstico de empiema e indicação de drenagem de tórax.9,20,26

A pneumatocele é uma cavidade pulmonar de paredes finas que pode ser complicação da PAC de qualquer etiologia. Embora seja mais caracteristicamente causada por estafilococos, nota-se sua maior frequência nas
PAC por Streptococcus pneumoniae. A radiografia de tórax é recomendada para seu diagnóstico. A tomografia computadorizada (TC) de tórax pode contribuir para o diagnóstico diferencial com pneumotórax, cistos pulmonares e para precisar sítio de drenagem percutânea quando necessário. Na maioria dos casos as pneumatoceles têm involução espontânea e o tempo para resolução pode ser de semanas até mais de um ano. Por isso, o tratamento geralmente é conservador. ${ }^{22}$

A pneumonia necrotizante ou necrosante pode se desenvolver como resultado de necrose alveolar ou bronquiolar localizada. Embora Streptococcus pneumoniae seja o principal agente etiológico, outras bactérias, como Staphylococcus aureus e anaeróbios, podem estar envolvidas. Portanto, a escolha terapêutica deve sempre contemplar uma cobertura mais ampla, conforme for a situação clínica e a frequência de resistência local. ${ }^{22,23}$

\section{TRATAMENTO}

Todos os casos de PAC considerados graves necessitam de hospitalização com antibioticoterapia adequada, hidratação venosa, terapia de suporte e uso de oxigênio. ${ }^{4,20,27-29}$

Outras indicações de internação além das citadas são: lactentes menores de 3 meses; $\mathrm{SO}_{2}$ menor que $92 \%$; cianose; FR maior ou igual a 70 rpm; dificuldade respiratória; apneia intermitente; gemência; impossibilidade de se alimentar. Em crianças entre 2 meses e 5 anos considerar: tiragem subcostal grave; gemência respiratória; cianose central; incapacidade de deglutição; $\mathrm{SO}_{2}$ menor que $92 \%$ em ar ambiente; crianças imunodeprimidas; falha da terapêutica ambulatorial; doença grave concomitante; sinais radiológicos de gravidade; questões sociais. ${ }^{9}$

As principais indicações para o tratamento em unidade de terapia intensiva são: $\mathrm{SO}_{2}$ menor que $92 \% \mathrm{com}$ $\mathrm{FiO}_{2}$ maior que 0,6 ; hipotensão arterial; falência respiratória; apneia recorrente ou respiração irregular., ${ }^{40,28,29}$

No caso dos pacientes internados, o tratamento das PAC é realizado de acordo com a principal suspeita etiológica. A grande dificuldade no diagnóstico etiológico faz com que a antibioticoterapia seja empírica, de acordo com o provável germe por faixa etária segundo a figura 4 .

A amoxicilina é a primeira opção terapêutica no tratamento ambulatorial, sendo recomendada para o tratamento da PAC em crianças de 2 meses a 5 anos, na dose de $50 \mathrm{mg} / \mathrm{kg} /$ dia de 8 em 8 horas.

Em crianças maiores ou com 5 anos, o fármaco de escolha também é amoxicilina nas mesmas doses. Devido à possibilidade de Mycoplasma pneumoniae, pode-se optar pela introdução de macrolídeos (pneumonia atípica), 


\section{TRATAMENTO HOSPITALAR DA PNEUMONIA COMUNITÁRIA}

\section{ASSIM QUE A CRIANÇA INTERNAR}

colher 2 amostras de hemocultura em momentos diferentes

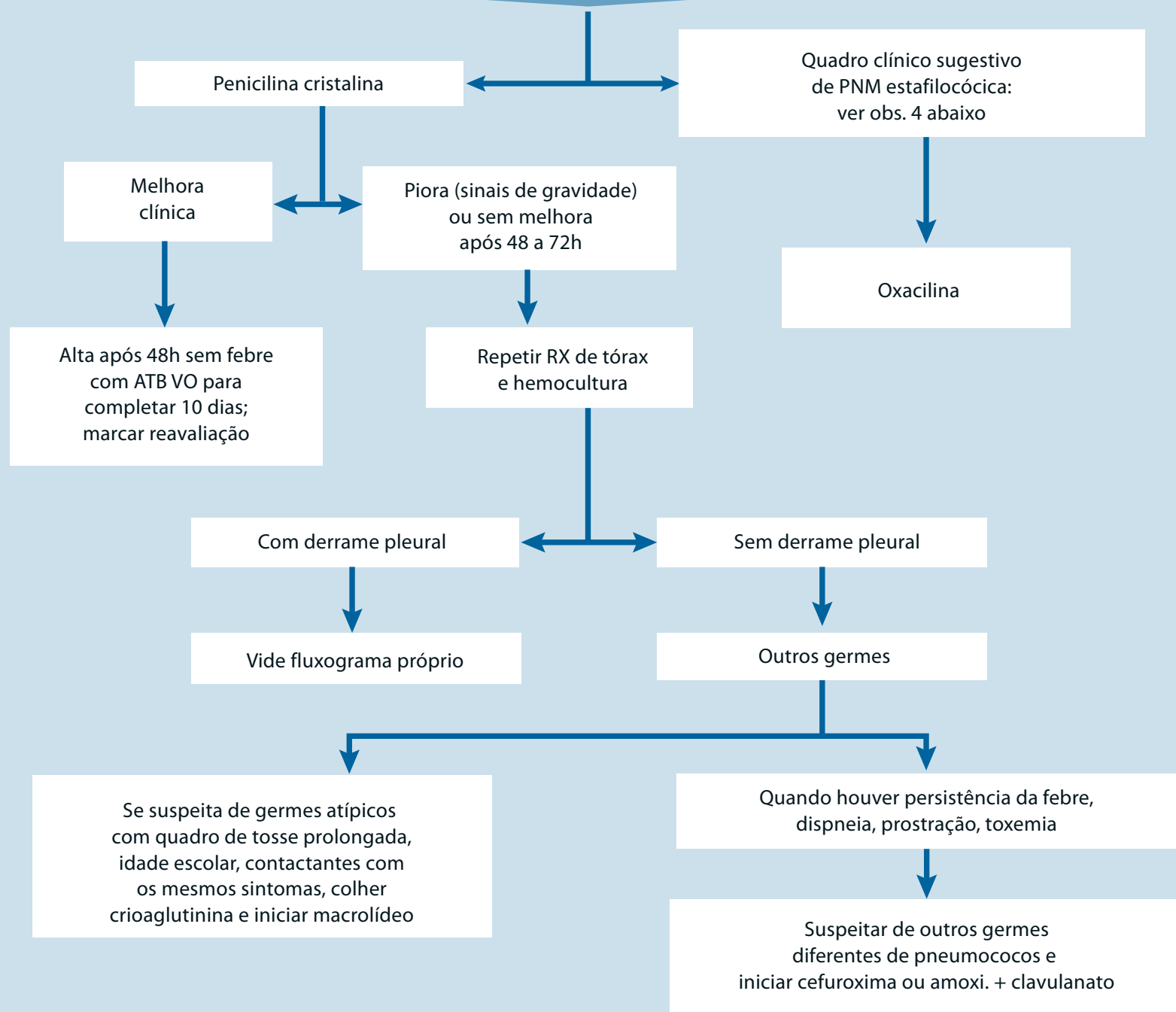

Fonte: Elaborada pelos Serviços de Pneumologia, Doenças Infecciosas e Parasitárias e Emergência do Instituto de Puericultura e Pediatria Martagão Gesteira da Universidade Federa do Rio de Janeiro (2018).

como eritromicina, claritromicina ou azitromicina. $\mathrm{O}$ tratamento inicial da PAC com macrolídeos em crianças maiores de 5 anos não tem se mostrado mais eficaz que o tratamento convencional com amoxicilina.

A OMS estabelece como critério de falha terapêutica para PAC não grave a não normalização da FR e/ou aparecimento de tiragem subdiafragmática ou de qualquer outro sinal de gravidade no terceiro dia de tratamento. ${ }^{4,20}$

Toda criança com PAC que tenha condições clínicas de ser tratada em seu domicílio deve ter uma consulta de reavaliação agendada após 48 a 72 horas na instituição do tratamento ou a qualquer momento se houver piora clínica. Caso apresente melhora, o tratamento deve ser mantido até completar sete dias. Por outro lado, se a criança estiver pior ou inalterada, cabe avaliar internação hospitalar. ${ }^{4,20}$

Os casos classificados como PAC graves devem ser encaminhados para tratamento hospitalar. A conduta nestes casos está contida na figura 5.,20

Usualmente indica-se o tratamento das PAC por um período de sete dias, podendo ser estendido em casos complicados. ${ }^{22}$ 


\section{TRATAMENTO HOSPITALAR DA PNEUMONIA COMUNITÁRIA COM DERRAME PLEURAL NA INFÂNCIA}

\section{PNM com derrame pleural}

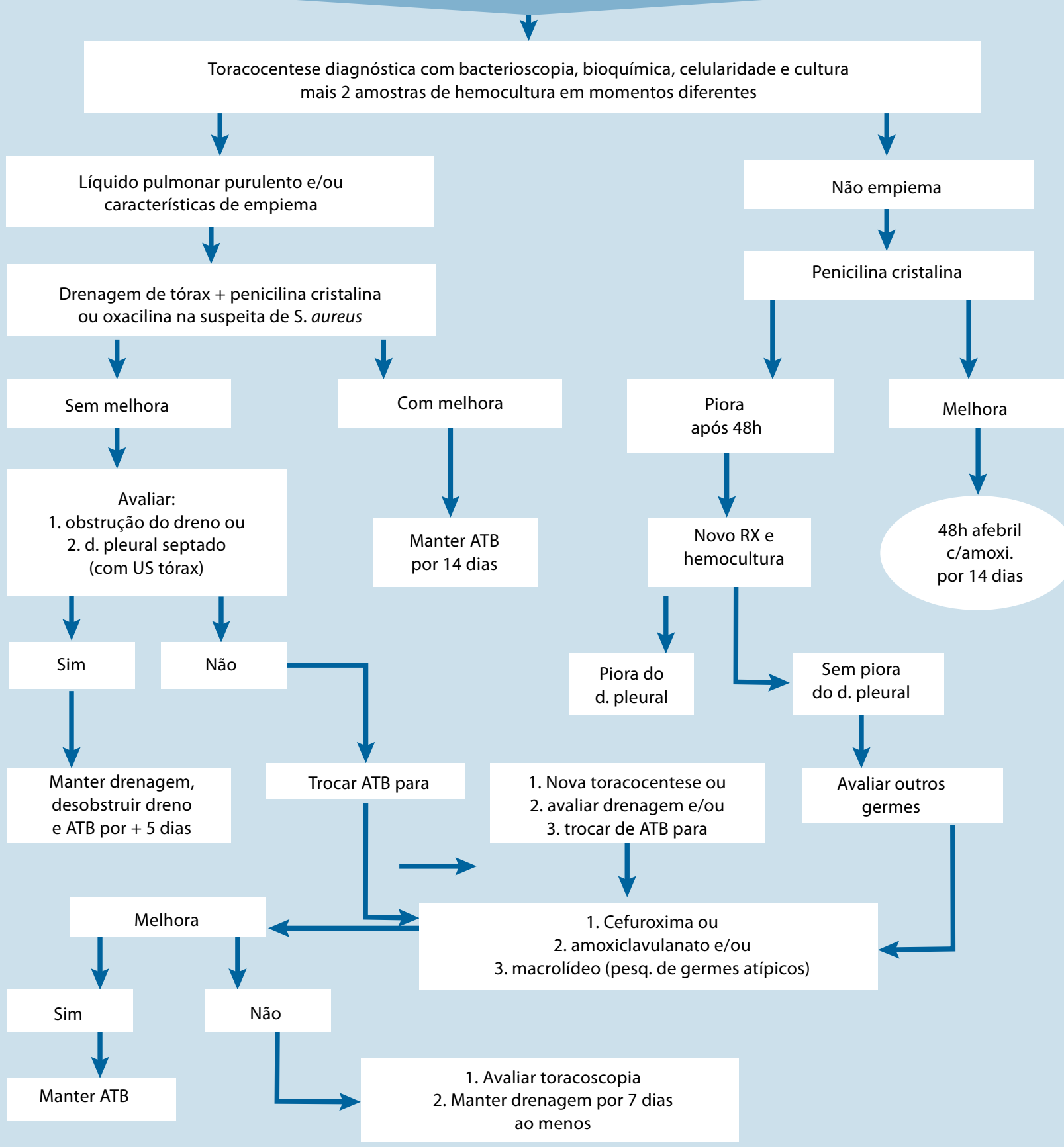

Obs.: 1. A toracocentese só será realizada quando o volume do derrame pleural for moderado a extenso. 2. Derrames pleurais de pequeno volume devem ser conduzidos como pneumonia comunitária comum.

3. Crianças de 2 a 6 meses de idade com conjuntivite e RX de tórax com infiltrado e estreitamento de mediastino, considerar pneumonia por Chlamydia e iniciar macrolídeo por 14 dias. 


\section{PREVENÇÃO}

Programas específicos para o controle da doença devem ser implementados: melhorias nas condições de saúde das crianças, assim como medidas de prevenção, por exemplo a vacinação PCV10 em massa.

Estudos nacionais identificaram que um ano após a introdução da PCV10 na rede pública de saúde houve redução das hospitalizações de crianças por PAC no Brasil. Em contrapartida, as internações por outras causas não diminuíram. , $30,31,32$ Quanto ao impacto da vacinação anti-Haemophilus influenzae tipo b na comunidade, há evidências de proteção contra a PAC na infância.

\section{PNEUMOCOCO}

Dentre as causas bacterianas das PAC, destaca-se o pneumococo, pela maior frequência, mesmo nos pacientes com derrame pleural. São cocos Gram-positivos, com mais de 90 sorotipos já identificados. A prevalência de cada sorotipo varia de acordo com a região. ${ }^{16-18}$ No Brasil, Cardozo e colaboradore ${ }^{17}$ identificaram os sorotipos $6 \mathrm{~B}$, $6 \mathrm{~A}, 23 \mathrm{~F}$ e $18 \mathrm{C}$ como os mais frequentes.

A mortalidade por PAC causada por pneumococo nas eras pré e pós-introdução da penicilina foram de $20 \%$ e $5 \%$, respectivamente. A penicilina foi o antibiótico de escolha para o tratamento de PAC por mais de 25 anos, sem alteração da sua eficácia.

\section{RESISTÊNCIA DO PNEUMOCOCO À PENICILINA}

A resistência adquirida de microrganismos como os pneumococos às penicilinas acontece a partir de alterações genéticas que ocorrem nas proteínas ligadoras da superfície, alterando sua estrutura e dessa forma reduzindo a afinidade da ligação da bactéria à penicilina. $\mathrm{O}$ grau de resistência de cada cepa é medido pelo nível da concentração inibitória mínima (MIC), ou seja, a concentração mínima de penicilina necessária para inibir a ação do pneumococo. ${ }^{33}$

Até recentemente, consideravam-se cepas resistentes à penicilina quando estas apresentavam MIC maior que 2 ug/ml e resistência intermediária quando o MIC era de 0,12-1 ug/ml. MIC menor que 0,12 era considerada sensível. Contudo, verificou-se que alguns pacientes, mesmo com valores de resistência alta, mostravam melhora clínica com o uso de penicilina. Esses estudos contribuíram para a modificação dos valores do MIC considerados como sensível, intermediário e resistente. Ultimamente utiliza-se o MIC menor ou igual a 2, MIC igual a 4 e MIC maior ou igual a 8 como sensível, resistência intermediária e resistência plena, respectivamente, segundo o Clinical and Laboratory Standards Institute. Esta nova padronização visa reduzir o número de pacientes considerados resistentes, cuja resposta clínica é satisfatória com o uso da penicilina. ${ }^{33}$

Estudos realizados em países desenvolvidos mostram cada vez mais o aumento da resistência pneumocócica à penicilina. ${ }^{22,33}$

Elevada resistência também foi observada nos EUA, porém em níveis mais baixos do que na Ásia. Na população americana, em 2004, os valores variavam de acordo com a região, sendo no sul e sudeste os maiores valores - de 33 a 36\%. Entretanto, na Espanha, de 2002 a 2007, houve aumento da resistência bacteriana sem crescimento na taxa de mortalidade dos pacientes com PAC por Streptococcus pneumoniae..$^{20,22}$

Com a introdução das vacinas antipneumocócicas (com ênfase para a 7 valente) houve aparente aumento da resistência bacteriana a partir da modificação dos principais sorotipos causadores da doença, sobretudo na Europa e nos EUA. Entretanto, houve redução da resistência às penicilinas como consequência da introdução da vacina pneumocócica conjugada entre 2004 e $2007 .{ }^{34}$

No Brasil, em 2006, a resistência pneumocócica foi mais encontrada com relação ao sorotipo 14 e houve aumento dos sorotipos de Streptococcus pneumoniae presentes na vacina antipneumocócica conjugada em pacientes com PAC. Essa vacina ainda não era administrada como rotina em todas as crianças do país, só em algumas com critérios específicos, como algumas doenças de base. Isso foi modificado em 2010, com sua introdução no calendário do Ministério da Saúde. 4,17,35-37

O estudo multicêntrico, observacional e prospectivo Caribe realizado na América Latina foi feito no período de julho 1998 a dezembro 2002. Contou com a participação de 12 centros de saúde, em três países diferentes: Brasil (cinco centros), Argentina (seis centros) e República Dominicana (um centro). Um dos centros que participou desse estudo foi o Instituto de Puericultura e Pediatria Martagão Gesteira (IPPMG) da Universidade Federal do Rio de Janeiro (UFRJ). ${ }^{33} \mathrm{O}$ objetivo foi verificar se a resistência do pneumococo à penicilina in vitro está relacionada à falência terapêutica dos pacientes com PAC tratados com penicilina ou ampicilina. Nesse estudo, quando o Streptococcus pneumoniae era identificado, o material era encaminhado para a análise do MIC. Este era determinado de acordo com as diretrizes da Clinical and Laboratory Standards Institute/National Committee for Clinical Laboratory Standards (CLSI/NCCLS) da época, que eram: sensível - maior ou igual a $0,06 \mu \mathrm{g} / \mathrm{ml}$; intermediário - de $0,12 \mu \mathrm{g} / \mathrm{ml}$ a $1 \mu \mathrm{g} / \mathrm{ml}$; e resistente maior ou igual a $2 \mu \mathrm{g} / \mathrm{ml} .{ }^{33}$ 
O pneumococo foi o agente etiológico em $11 \%$ dos casos de PAC. Quanto à determinação da sensibilidade in vitro, $52 \%$ eram sensíveis, $26 \%$ com sensibilidade intermediária e $22 \%$ resistentes. Quando analisadas as culturas apenas do Brasil, 47\% eram sensíveis, 31\% intermediárias e $14 \%$ resistentes. ${ }^{17}$

Houve falha terapêutica em $21 \%$ dos casos, sem evidências de associação entre a falha e a resistência bacteriana observada in vitro. Concluiu-se que o uso da penicilina como primeira escolha ainda é válido e eficaz para o tratamento das PAC. ${ }^{33}$ Vale ressaltar que o trabalho foi realizado no período dos antigos critérios para corte e definição do MIC como pneumococo sensível, intermediário ou resistente. Se reclassificadas as cepas de acordo com os critérios atuais de MIC para penicilina, constata-se que nenhuma seria considerada resistente. ${ }^{33}$

\section{VACINAS ANTIPNEUMOCÓCICAS}

Desde 2000 a PCV7 é utilizada nos EUA, tendo sido substituída em 2010 pela PCV13. No Brasil, a PCV7 foi incorporada no calendário vacinal em 2002 apenas para crianças menores de 5 anos e para aquelas com fatores de risco e comorbidades. Em julho de 2010, a PCV10 foi introduzida para crianças menores de 3 anos junto com a vacina polissacarídica 23 valente (PPV23), oferecida para maiores de 2 anos com fatores de risco para infecção pneumocócica. A PCV10 foi implantada no calendário vacinal brasileiro incluindo os mesmos sorotipos da PCV7 (4, 6B, 9V, 14, 18C, 19F, 23F) acrescida dos sorotipos 1,5 e $7 \mathrm{~F} .{ }^{31}$

Vacinas conjugadas são aquelas nas quais os antígenos bacterianos são ligados a carreadores proteicos, facilitando o processamento pelos linfócitos $\mathrm{T}$, gerando então uma resposta de longa duração de anticorpos protetores mesmo em lactentes jovens. Na PCV10 o carreador proteico para oito dos seus sorotipos $(1,4,5,6 \mathrm{~B}, 7 \mathrm{~F}, 9 \mathrm{~V}$, 14 e 23F) é a proteína D do Haemophilus influenzae não tipável e para os outros dois sorotipos (19F e 18C) é a proteína carreadora de toxoide diftérico. ${ }^{37,38}$

Os efeitos principais da PCV10 são: a prevenção da doença pneumocócica invasiva (pneumococo é o segundo agente etiológico mais comum nas meningites bacterianas), PAC, otite média aguda. A vacinação reduz o estado de portador de bactéria em nasofaringe e vias aéreas superiores e possui efeito de rebanho, que traz benefícios indiretos na redução das doenças mesmo nas pessoas não vacinadas. ${ }^{38}$

As indicações das vacinas variam de acordo com a idade e comorbidades associadas no paciente. As principais indicações são: crianças menores de 23 meses que apresentam alto risco para infecção pneumocócica (hemoglobinopatias, asplenia, HIV, imunodeficiências, neoplasias, doença renal crônica ou síndrome nefrótica, uso de terapia imunossupressora ou uso prolongado de corticoide sistêmico, doenças crônicas, pacientes transplantados. ${ }^{15,30}$ Além das indicações acima, outras crianças podem se beneficiar da vacina: aquelas entre 2 e 3 anos de idade e as menores de 5 anos que frequentam creches.

O esquema vacinal adotado no Brasil em 2010 foi o de três doses e um reforço, e em 2016 foi modificado para duas doses e um reforço. Estudos mostram que o esquema de duas doses é tão efetivo quanto o de três, com o benefício de diminuir muito o custo da vacinação em ampla escala. ${ }^{37-39}$

A PCV13 é a preconizada nos EUA e também está disponível na rede particular no Brasil. Além dos mesmos sorotipos cobertos pela PCV10 (1, 4, 5, 6B, 7F, 9V, 14, 23F, 19F e 18C), essa vacina ainda cobre três sorotipos adicionais (3, 6A e 19A), aumentando para $92 \%$ a cobertura vacinal para prevenção da doença pneumocócica invasiva em lactentes e crianças pequenas em todo o mundo. ${ }^{19}$ No Brasil, a PCV13 representaria a possibilidade de prevenção de $87 \%$ dos casos de doença pneumocócica invasiva em crianças menores de 5 anos de idade. ${ }^{37,38}$

A PCV23 está licenciada desde 1983 e é indicada para pacientes adultos de alto risco e idosos. A vacina contém antígeno polissacarídeo para os 23 sorotipos mais dominantes responsáveis por aproximadamente $90 \%$ das doenças pneumocócicas invasivas. Crianças menores de 2 anos e adultos em vários estados de imunodeficiência não desenvolvem a imunidade adequadamente. A resposta de indução de anticorpos é satisfatória e necessária, principalmente em pacientes idosos. ${ }^{37,38}$

Antes da imunização com as vacinas antipneumocócicas conjugadas nos EUA, o Streptococcus pneumoniae era responsável por aproximadamente 17.000 casos de doença invasiva em menores de 5 anos anualmente, incluindo 700 casos de meningite e 200 óbitos. Era a causa mais frequente de bacteremia, PAC, meningite bacteriana, sinusite e otite média aguda (OMA) ${ }^{38}$ Estudos brasileiros já apontam bons resultados após implementação no calendário vacinal. Em estudo feito em 2013 foram analisadas 197.975 hospitalizações das quais 30\% eram causadas por PAC, após um ano da introdução da vacina. Apontou declínio em algumas cidades, como Belo Horizonte $(28,7 \%)$, Curitiba $(23,3 \%)$ e Recife $(27,4 \%) .{ }^{35}$ Outro estudo feito em São Paulo após dois anos da vacinação observou significativa redução nos quadros de doença invasiva pneumocócica. ${ }^{31}$

Estudo mais recente de 2016 comparando a era pré e 
pós-vacinal em relação ao número de hospitalizações e mortes mostrou redução de 19\% de PAC em menores de 1 ano. ${ }^{31}$ Estudo locorregional feito em Santa Catarina também chegou à conclusão de redução de $11 \%$ na taxa média de mortalidade por PAC em menores de 1 ano nos quatro primeiros anos de implantação da vacina naquele estado.

\section{CONSIDERAÇÕES FINAIS}

As PAC podem ser de etiologia variada, mas destaca-se o Streptococcus pneumoniae (pneumococo) como o seu principal agente etiológico. Achados clínicos são os mais valorizados no diagnóstico das PAC na infância. O tratamento com antibióticos betalactâmicos (penicilina e derivados) continua sendo indicado no Brasil, uma vez que se considera que as cepas causadoras de PAC no nosso meio são sensíveis a este antibiótico.

A prevenção das PAC com vacinas antipneumocócicas conjugadas trouxe auxílio importante no controle da doença. A disponibilidade da vacina PCV10 no calendário básico de imunização no Brasil contribuiu para a redução da hospitalização por PAC em crianças nos estudos desenvolvidos no país.

\section{REFERÊNCIAS}

1 Wardlaw TM, Johansson EW, Hodge M; World Health Organization; United Nations Children's Fund. Pneumonia: the forgotten killer of children. WHO/UNICEF, 2006 [access on Jan 14, 2017] . Available from: http://apps.who.int/ iris/bitstream/handle/10665/43640/9280640489_eng. pdf; jsessionid=23EB2C38CE6E99C17420A5F4D54ABA65? sequence $=1$

2 Rodrigues FE, Tatto RB, Vauchinski L, Leães LM, Rodrigues MM, Rodrigues VB et al. Pneumonia mortality in Brazilian children aged 4 years and younger. J Pediatr (Rio J). 2011;87(2):111-4.

3 Axelsson I, Silfverdal SA. Pneumonia mortality among children in Brazil: a success story. J Pediatr (Rio J). 2011;87(2):85-7.

4 Sociedade Brasileira de Pneumologia e Tisiologia. Diretrizes Brasileiras em Pneumonia Adquirida na Comunidade em Pediatria. J Bras Pneumol. 2007;33(Supl 1):S31-50.

5 Mcintosh K. Community-acquired pneumonia in children. N Engl J Med. 2002;346(6):429-37.

6 American Academy of Pediatrics. Pneumococcal infections. In: Kimberlin DW, Brady MT, Jackson MA, Long SS (Eds). Red book: 2015 report of the Committe on Infectious Diseases. $30^{\text {th }}$ ed. American Academy of Pediatrics; 2015. p. 626.

7 Centers for Disease Control and Prevention. Pneumococcal vaccination [access on Dez 28, 2016]. Available from: https:// www.cdc.gov/vaccines/vpd/pneumo/index.htm

8 Wexler Id, Knoll S, Picard E, Viela Y, Shoseyov D, Engelhard D et al. Clinical characteristics and outcome of comlicated pneumococcal pneumonia in a pediatric population. Pediatr Pulmonol. 2006;41(8):726-34.

9 March MFBP, Ferreira S, Ribeiro JD, Souza ELS. Pneumonias comunitárias. In: Campos Jr D, Burns DAR, Lopez FA. Tratado de Pediatria. 3. ed. São Paulo: Manole; 2013. p. 2549-58.

10 Macedo SEC, Menezes AMB, Albernaz E, Post P, Knorst M. Fatores de risco para internação por doença respiratória aguda em crianças até um ano de idade. Rev Saúde Pública. 2007;41(3):351-58.

11 Goya A, Ferrari GF. Fatores de risco para morbimortalidade por pneumonia em crianças. Rev Paul Ped. 2005;23(2):99-105.

12 César JA, Victora CG, Santos IS, Barros FC, Albernaz EP, Oliveira LM et al. Hospitalização por pneumonia: influência de fatores socioeconômicos e gestacionais em uma coorte de crianças no Sul do Brasil. Rev Saúde Públ. 1997;31 (1):53-61

13 March MFBP, Sant'Anna CC. Signs and symptoms indicative of community-acquired pneumonia in infants under six months. Braz J Infect Dis. 2005;9(2):150-5.

14 Maia PN. Padronização de rotinas em crianças com PAC com e sem comorbidades. Rio de Janeiro. Dissertação [Mestrado em Clínica Médica] - Universidade Federal do Rio de Janeiro; 2014.
15 Principi N, Esposito S. Management of severe communityacquired pneumonia of children in developing and developed countries. Thorax. 2011;66(9):815-22.

16 Brandileone MC, Vieira VS, Casagrande ST, Zanella RC, Guerra ML, Bokermann S et al. Prevalence of serotypes and antimicrobial resistance of Streptococcus pneumoniae strains isolated from Brazilian children with invasive infections. Pneumococcal Study Group in Brazil for the SIREVA Project. Regional System for Vaccines in Latin America. Microb Drug Resist. 1997;3(2):141-6.

17 Cardozo DM, Nascimento-Carvalho CM, Brandão MA, Azevedo GM, Ribeiro de Souza F, Silva NM et al. Antimicrobial resistance and serotypes of nasopharyngeal strains of Streptococcus pneumoniae in Brazilian adolescents. Microb Drug Resist. 2006;12(1):29-32.

18 Pelton SI, Hammerschlag MR. Overcoming current obstacles in the management of bacterial communityacquired pneumonia in ambulatory children. Clin Pediatr (Phila). 2005 44(1):1-17.

19 César JA, Victora CG, Barros FC, Santos IS, Flores JA. Impact of breast feeding on admission for pneumonia during postneonatal period in Brazil: nested case-control study. BMJ. 1999;318(7194):1316-20.

20 Ross RK, Hersh AL, Kronman MP, Newland JG, Metjian TA, Localio AR et al. Impact of Infectious Diseases Society of America/Pediatric Infectious Diseases Society guidelines on treatment of community-acquired pneumonia in hospitalized children. Clin Infect Dis. 2014;58(6):834-8.

21 Lucarevschi BR, Baldacci ER, Bricks LF, Bertoli CJ, Teixeira LM, Mendes CMF et al. Oropharyngeal carriage of Streptococcus pneumoniae by children attending day care centers in Taubaté, SP: correlation between serotypes and the conjugated heptavalent pneumococcal vaccine. J Pediatr (Rio J). 2003;79(3):215-20.

22 Jain S, Williams DJ, Arnold SR, Ampofo K, Bramley AM, Reed C et al. Community-acquired pneumonia requiring hospitalization among U.S. children. N Engl J Med. 2015;372:835-45.

23 Woods CR, Bryant KA. Viral infections in children with community-acquired pneumonia. Curr Infect Dis Rep. 2013;15(2):177-83.

24 Ferreira S, Sant'Anna CC, March MFBP, Santos MARC, Cunha AJLA. Lethality by pneumonia and factors associated to death. J Pediatr (Rio J). 2014;90(1):92-7.

25 Stein RT, Marostica PJC. Community-acquired bacterial pneumonia. In: Chernick V, Boat TF, Wilmott RW, Bush A. Kendig's disorders of the respiratory tract in children. $7^{\text {th }}$ ed. Elsevier, 2006. p. 441-52.

26 British Thoracic Society; Community Acquires Pneumonia in Children Guideline Group. Guidelines for the management of comunity acquires pneumonia in children: update 2011. 
Thorax. 2011;66(Suppl 2):iil-23.

27 Leite CR, Azevedo J, Galvão VS, Moreno-Carvalho O, Reis JN, Nascimento-Carvalho C. Clinical and bacteriological characteristics of invasive pneumococcal disease after pneumococcal 10-valent conjugate vacine implementation in Salvador, Brazil. Braz J Infect Dis 2016;20(1):56-60.

28 Ferreira S, March MFBP. Tratamento das pneumonias comunitárias na infância. Pulmão RJ. 2009;(Supl 1):S50-3.

29 Lotufo JPB, Lederman HM. Radiologia de tórax para o pediatra: clínica de tórax para o radiologista. São Paulo; s.n; 2009.

30 Kupek E, Vieira ILV. O impacto da vacina pneumocócica PCV10 na redução da mortalidade por pneumonia em crianças menores de um ano em Santa Catarina, Brasil. Cad Saúde Pública. 2016;32(3):e00131414.

31 Santos SR, Passadore LF, Takagi EH, Fujii CM, Yoshioka CRM, Gilio AE et al. Serotype distribution of Streptococcus pneumoniae isolated from patients with invasive pneumococcal disease in Brazil before and after tenpneumococcal conjugate vaccine implementation. Vaccine. 2013;31(51):6150-4.

32 Ferreira S. Tratamento empírico com penicilina em crianças internadas com pneumonia adquirida na comunidade em um hospital universitário pediátrico no Rio de Janeiro: perfil clínico e estudo da letalidade. Tese [Doutorado em Clínica Médica] - Universidade Federal do Rio de Janeiro; 2012.
33 Cardoso MRA, Nascimento-Carvalho CM, Ferrero F; Berezin EN, Ruvinsky R, Camargos PA et al. Penicillin-resistant pneumoccocus and risk of treatment failure in pneumonia. Arch Dis Child. 2008;93(3):221-5.

34 Silva SR, Mello LM, Silva AS, Nunes AA. Impacto da vacina antipneumocócica 10 valente na redução de hospitalização por pneumonia adquirida na comunidade em crianças. Rev Paul Pediatr. 2016:34(4):418-24.

35 Afonso E, Minamisava R, Bierrenbach A, Escalante J, Alencar A, Domingues $C$ et al. Effect of 10 -valent pneumococcal vaccine on pneumonia among children, Brazil. Emerg Infect Dis. 2013;19(4):589-97.

36 Plosker GL. 10-Valent pneumococcal non-typeable haemophilus influenzae protein $\mathrm{D}$-conjugate vaccine: a review in infants and children. Paediatr Drugs. 2014; 16(5):425-44.

37 Croxtall JD, Keating GM. Pneumococcal polysaccharide protein D-conjugate vaccine (Synflorix; PHiD-CV). Paediatr Drugs. 2009;11(5):349-57.

38 Advisor Committe on Immunization Practices. Preventing pneumococcal disease among infants and young children: recommendations of the Advisory Committe on Immunization Practices (ACIP). MMWR Recomm Rep. 2000;49(RR-9):1-35.

39 Brasil. Ministério da Saúde. Calendário Nacional de Vacinação [acesso em 21 nov 2018]. Disponível em: http:// portalms.saude.gov.br/acoes-e-programas/vacinacao/ calendario-vacinacao 